\title{
EDITORIAL
}

\section{Comparative Effectiveness Research: Medical Practice, Payments, and Politics: the Need to Retain Standards of Medical Research}

\author{
Harry P. Selker, MD, MSPH ${ }^{1,2}$ \\ IInstitute for Clinical Research and Health Policy Studies, Tufts Medical Center, Boston, MA, USA; ${ }^{2}$ Tufts Clinical and Translational Science \\ Institute, Tufts University, Boston, MA, USA.
}

J Gen Intern Med 24(6):776-8

DOI: $10.1007 / \mathrm{s} 11606-009-0988-7$

(c) Society of General Internal Medicine 2009

$\mathrm{C}$ omparative effectiveness research (CER), once only the scientific interest of clinical and health services researchers who compared medical treaments, now has tumbled into the public arena. $\left({ }^{1}\right)$ Facing the need for drastic improvement in our nation's healthcare delivery, Congress and the Obama Administration are looking to CER to improve and broaden the use of treatments in a cost-effective way. Researchers, clinicians, professional societies, and policy experts have welcomed this, as they see CER as a scientifically rigorous way to select the most effective treatments for the benefit of patients and the public. On the other hand, while there has been support in the healthcare industry, apprehension has surfaced among those whose products would be subject to evaluation of effectivness, including pharmaceutical, biotech, and medical device companies, and among those who pay for treatments, including health plans, insurers, and large employers. Such concerns have translated into intense politics around CER-perhaps the best evidence that CER is truly likely to change practice and payment for medical care. This intensity also serves to remind us why, for CER, we must retain the usual standards and structures for medical research.

Potential outcomes of CER include scientific knowledge, improved health, and financial impact. $\left({ }^{2}\right)$ In terms of science, across the spectrum of CER, from structured analyses of prior studies, databases, and registries, to the conduct of large clinical effectiveness trials, the scientific objective is rigorous reliable information about what treatments are best for what patients, and under what circumstances. Unless the conduct or public release of such research is compromised by poor quality or conflicts of interest, such information should have a direct positive impact on health.

The economic consequences are less direct. For the nation, whatever the total costs of healthcare, CER should have a positive impact on cost-effectiveness-we would be spending healthcare dollars more wisely, on the most effective care, as concluded by detailed analyses by the Congressional Budget Office. ${ }^{3-5}$ ) However, for those who sell treatments, the consequences are mixed. Pharmaceutical manufacturers may benefit financially because CER will compare drugs to not only

Published online May 1, 2009 other drugs, but also to medical devices and procedures, which could expand the conditions for which their drugs might be used, and thus would enlarge their market. However, some new on-patent drugs may be found to be no more effective than earlier off-patent versions already generically available at far less cost, and this could compromise sales of their most profitable drugs. Similarly, for medical device companies, profits could be reduced. Because currently FDA's statute mandates less evidence of treatment benefit for medical devices than for drugs, a new requirement for rigorous testing of effectiveness would require extra time and money, and ultimately likely would show that at least some devices have undiscernable treatment benefits, which would curtail sales.

These adverse effects on manufacturers' profits are the other side of the coin that should result in greater costeffectiveness, which should be attractive to healthcare payers, including insurers, self-insured companies, and the government. Reliable well-accepted information on treatment effectiveness on which to base payment decisions would be very helpful. Moreover, that such information would be generated without insurers using their own funds, and without violating anti-trust rules against colluding with competitors about business decisions, but rather using public funds, is very attractive. However, the possibility that they may be mandated to provide access to treatments found to be effective and that their decision-making about payment would be potentially limited, based on such data, is of concern.

These business concerns have generated political action. While expressing general support for CER, industry interests have conducted a two-pronged approach to alter CER legislation. First, they want to be sure that cost-effectiveness is not part of CER. Manufacturers fear impediments to sales of their most profitable products, and healthcare payers fear impediments to their healthcare coverage decisions. Manufacturers' lobbyists have pressured Congressional offices involved in healthcare policy that have included CER in proposed legislation, insisting that cost-effectiveness analyses be specifically precluded from CER. Also, there has been a public campaign to raise fears about CER intended to influence Congress. For example, when in mid-February 2009 CER appeared likely to be part of the American Recovery and Reinvestment Act, commentary and editorials on Fox News, the Wall Street Journal, and other outlets, and commentators such as Lou Dobbs and Rush Limbaugh warned that CER would lead to government restrictions in treatments based on cost, and that old people would be denied all costly medical treatments under 
a new "duty to die" regime meant to save money, a type of government-mandated "Nazi-style euthanasia." ${ }^{6-8}$ ) The 2year economic stimulus funding of CER was retained in this legislation, but the discourse gave a sample of what might be in store for the inclusion of CER in long-term healthcare reform.

Second, if CER is to be done, industry wants "stakeholder" input into its conduct, and wants it not to be done at a current Federal medical or healthcare research agency. What are the alternatives? Currently, the private sector puts a relatively small amount of financial resources toward CER, focused on products or services of specific companies. The objectivity of this research is suspect, and, as has become too evident recently, results may be buried if not in concert with a company's objectives, even if they would have been helpful to the healthcare system and the health of the public. In comparison, the Agency for Healthcare Research and Quality (AHRQ), already mandated by law to do CER, and the National Institutes of Health (NIH), where CER is also done, both have long-standing high standards of research transparency and disclosure, with results available for public scrutiny. The credibility of these science agencies has led to acceptance of their findings by the medical community and dissemination of practice improvements, supporting improved care by all clinicians and payers.

Despite this, business interests continue to press that CER not be done in these research agencies, but in entities such as a federally funded research and development center (FFRDC). This would allow governing input by industry stakeholders, and the entity would not be subject to the rules, regulations, and laws that govern the conduct of science at federal research agencies, and it would not be protected from political pressure. $\left({ }^{1,9}\right)$ Proponents of this approach state that AHRQ is vulnerable to political influence, but the fact that the proposed alternatives are much more susceptible to industry influence reveals the real concern about keeping CER with other federally sponsored medical research in Federal research agencies-the possibility of lack of outside influence. (Of note, AHRQ's predecessor agency was slated for elimination in 1997 after subgroups in the orthopedic community became upset with a practice guideline it generated with regard to low back pain treatment and found a Congressional champion to seek elimination of the Agency. After that, wisely, the Agency stopped creating practice guidelines, instead focusing on compiling the evidence that others could use, the model for CER in a science agency.) In conjunction with this, AHRQ, currently the primary site for CER, has also been labeled as an example of an inefficient government agency. However, creating a completely new entity and research infrastructure and processes to replace what already is in place doing this work as a highly respected science agency seems far less efficient; the true objective seems something other than efficiency.

The stakes are very high-for industry, but also for the nation and for the public. There is ample recent history of industry influencing the public and government, and aborting or greatly modifying healthcare legislation. $\left({ }^{10}\right)$ There is a high road, a road that has made the biomedical research of this nation the best on the planet: the retention of the longdeveloped peer-review processes and increasingly strict protections against conflicts of interest embedded in the operations of the NIH, AHRQ, National Science Foundation (NSF), and other Federal research agencies. On the other hand, industry concern about CER being done in a Federal research agency does have merit. Such research should generate information that will help those who make healthcare payment coverage decisions, and such research should not be restricted for political reasons, but payment for treatments should not be the purview of the science agencies-these decisions should be made by other entities under the extant rules for healthcare coverage. This leads to specific recommendations for the conduct of CER:

(1) Comparative effectiveness research is research intended to affect treatments of people, and for that reason, like all biomedical research, it deserves to be done at the highest standards of science and free from conflicts of interest. Thus, it should be done at a science agency, not at a new hybrid entity that will have to build an entirely new science infrastructure and that will involve in its governance those with a direct stake in the results. Indeed, the latter risks a situation rife with conflict of interest and compromised scientific quality.

However, public input to the research agenda is a social good, and should be sought. It is very reasonable that agencies doing CER and healthcare research have a high-level public/ private advisory board. However, it must not be a governing board, which would constitute an avenue for conflict of interest that scientists, clinicians, policy-makers, and the public would find objectionable.

The AHRQ has the most broad experience and expertise for CER, and probably should be the lead agency for CER, but NIH also has a very important role to play, and both are likely to benefit from collaboration with the FDA, CDC, and other agencies. For example, based on these agencies' respective expertise, AHRQ could be responsible for research looking at effectiveness, harm, and safety done by analyses of current evidence, healthcare databases, and healthcare delivery, and NIH could be responsible for large randomized comparative effectiveness trials needed to accurately assess benefits of a treatment. A joint committee could coordinate these efforts, much as there is currently cooperation among program staff among the agencies for joint projects, and this would presumably be synchronous with the newly appointed Federal Coordinating Council for Comparative Effectiveness Research. Also, this link may be facilitated by the NIH Clinical and Translational Science Awards (CTSAs). With the mission of promoting of the wide spectrum of research that can improve the public's health, many CTSA institutions already have AHRQ CER centers [e.g., AHRQ Evidence-based Practice Centers, AHRQ/FDA Centers for Education and Research on Therapeutics, and AHRQ DeCIDE (Developing Evidence to Inform Decisions about Effectiveness) Network centers], and thus could be an excellent link to AHRQ around CER and a portal to NIH Institutes and Centers, and potentially to other agencies.

(2) Coverage decisions (or selective reimbursement and/or differential cost sharing) should not be the purview of the CER done at these research agencies; those decisions would be made at the Centers for Medicare and Medicaid Services (CMS) and other payers, as they are now. Presumably this will be addressed as part of the Healthcare Reform effort. Assessments of the effectiveness of treatments should be central to the output of CER; specific payment decisions about issues of policy, cost, equity, compassionate care, among many, should not be done in the research agencies. $\left.{ }^{10}\right)$ This should be overseen by regulatory agencies under long-established procedures. 
The American Recovery and Reinvestment Act of 2009 contained \$1.1 billion for CER activities at AHRQ and NIH. It was an excellent sign that the Government recognizes the importance of CER, and that its proper home is in a science agency, viz., AHRQ, in conjunction with $\mathrm{NIH}$, where peer review processes and research infrastructure are in place to ensure the highest quality science. This will benefit the entire healthcare system and the public through promoting more effective care. As the impact CER might have on payments plays out in politics, it is important for the nation and its citizens that CER not be rent asunder from the rest of the biomedical research enterprise. The opportunity to broaden and improve medical practice for all deserves our best efforts.

Corresponding Author: Harry P. Selker, MD, MSPH, Institute for Clinical Research and Health Policy Studies, Tufts Medical Center, and Tufts Clinical and Translational Science Institute, Tufts University, Boston, MA, USA (e-mail: hselker@tuftsmedicalcenter.org).

\section{REFERENCES}

1. Rich, EC. The policy debate over public investment in comparative effectiveness research. JGIM 10.1007/s11606-009-0958-0

2. Clancy CM. Getting to 'smart' health care. Health Affairs. 2006 November; 25:w589-w592.

3. The long-term outlook for health care spending. Washington, D.C: Congress of the U.S., Congressional Budget Office; 2007.

4. Orszag PR, Ellis $\mathbf{P}$. The challenge of rising health care costs-a view from the Congressional Budget Office. N Engl J Med. 2007;357(18): 1793-5.

5. Orszag PR, Ellis P. Addressing rising health care costs-a view from the Congressional Budget Office. N Engl J Med. 2007;357(19):1885-7.

6. Pearlstein S. Bloviation vs. Reality on Stimulus Health-Care Provision. Washington Post; Friday, February 13, 2009: D01.

7. Pear R. U.S. to Compare Medical Treatments. The New York Times. February 15, 2009.

8. Levey NN. A warning shot in the healthcare fight. Los Angeles Times; February 24, 2009.

9. Daschle T, Lambrew JM, Greenberger SS. Critical: What We Can Do About the Health Care Crisis. St. Martin's Press, February 2008.

10. Wilensky GR. Cost-effectiveness information: yes, it's important, but keep it separate, please!. Ann Intern Med. 2008;148(12):967-68. 